\title{
Wet deposition of hydrocarbons in the city of Tehran-Iran
}

\author{
Mohammad Ali Zahed • Alireza Pardakhti • \\ Leila Mohajeri • Farshid Bateni
}

Received: 3 August 2009 /Accepted: 15 September 2009/Published online: 11 November 2009

(C) The Author(s) 2009. This article is published with open access at Springerlink.com

\begin{abstract}
Air pollution in the city of Tehran has been a major problem for the past three decades. The direct effects of hydrocarbon contaminants in the air are particularly important such as their carcinogenic, mutagenic, and teratogenic effects which can be transported to other environments via dry and wet deposition. In the present study, rainwater samples were collected and analyzed for 16 polycyclic aromatic hydrocarbons (PAHs), benzene, toluene, ethyl benzene, and xylene (BTEX) as well as fuel fingerprints in two ranges of gasoline $(\mathrm{C} 5-\mathrm{C} 11)$ and diesel fuel (C12-C20) using a gas chromatograph equipped with a flame ionization detector (GC/FID). Mean concentrations of $\sum 16$ PAHs varied between 372 and $527 \mu \mathrm{g} / \mathrm{L}$ and for BTEX was between 87 and $188 \mu \mathrm{g} / \mathrm{L}$ with maximum of $36 \mu \mathrm{g} / \mathrm{L}$ for toluene. Both gasoline range hydrocarbons (GRH) and diesel range hydrocarbons (DRH) were also present in the collected rainwater at concentrations of 190 and $950 \mu \mathrm{g} / \mathrm{L}$, respectively. Hydrocarbon transports from air to soil were determined in this wet deposition. Average hydrocarbon transportation for $\sum$ PAHs, BTEX, GRH, and DRH was $2,747,627,1,152$, and $5,733 \mu \mathrm{g} / \mathrm{m}^{2}$, respectively.
\end{abstract}

Keywords Wet deposition - Rainwater Hydrocarbon . PAHs $\cdot$ BTEX $\cdot$ Air pollution $\cdot$ Tehran $\cdot$ Iran

M. A. Zahed $(\bowtie) \cdot$ L. Mohajeri $\cdot$ F. Bateni

School of Civil Engineering, Universiti Sains Malaysia,

14300 Nibong Tebal, Penang, Malaysia

e-mail: zahed51@yahoo.com

A. Pardakhti

Faculty of Environment, Tehran University,

P.O. Box 14155-6135, Tehran, Iran

\section{Introduction}

The World Health Organization states that 2.4 million people die annually from causes directly attributable to air pollution (WHO 2008). The hydrocarbon pollutants are especially important in the formation of secondary pollutants such as "photochemical smog" in the atmosphere. The direct effects of hydrocarbon contaminants in the air are particularly important such as their carcinogenic, mutagenic, and teratogenic effects (Maskaoui and $\mathrm{Hu}$ 2009; Yang et al. 2008; Zrafi-Nouira et al. 2008). The aromatic hydrocarbons such as benzene, toluene, ethyl benzene, xylene (BTEX), and the polycyclic aromatic hydrocarbons (PAHs) are of extreme importance among the hydrocarbon contaminants due to their dangerous consequences (Futoma et al. 1981). PAHs are composed of two or more fused aromatic rings of carbon and hydrogen atoms. The US Environmental Protection Agency (USEPA) has listed 16 PAHs as priority pollutants (USEPA 1993), and they have been classified into probable or possible human carcinogens by the International Agency for Research on Cancer (2008). Carcinogenicity of polycyclic aromatic hydrocarbons was reported by Sundberg and co-authors in 1998 and exposure to polycyclic aromatic hydrocarbons and their carcinogenic potencies from vehicle engine investigated by Tsai et al. (2004). The effects of PAHs upon the cytochrome P450 monooxygenase system were also widely investigated (Zhang et al. 2006; Roos et al. 2002; Achazi et al. 1998).

The main source of PAHs in the environment is incomplete combustion of modern biomass such as wood and fossil fuels including petroleum and coal. In the cities, traffic has been known to be the greatest PAH sources (Tsai et al. 2004). Menichini et al. (1999) carried out a study in a medium traffic area in Rome to investigate polycyclic aromatic hydrocarbons. 
The air pollution in the city of Tehran, Iran is mainly due to the fact that the city is surrounded by the Alborz Mountains and is also climatically very prone to the inversion phenomena. There are over one million automobiles, thousands of factories, and over ten million people living in the city of Tehran. The air pollutants in Tehran include hydrocarbons, halogenated compounds, heavy metals, NOx, SOx, and many others.

Several reports have been published on Tehran air quality (Kakooei et al. 2009; Hosseinpoor et al. 2005; Yokoyama and Takahashi 2003; Shirazi and Harding 2001; Asl-Soleimani et al. 2001; Sohrabpour et al. 1999), but a few articles have an approach to hydrocarbon pollution, Halek et al. (2008) evaluated PAHs in the gas phase in Iranian urban atmosphere. Jafari and Ebrahimi (2007) determined the concentration of benzene in Tehran air and estimated the cancer risk assessment of benzene. Pardakhti et al. (2004) investigated quantity of polycyclic aromatic hydrocarbons in the ambient air of the city of Tehran, and Esmaili-Sari (1997) reported the amount of PAHs compounds in Tehran air via wet deposition.

The current study is focused on the determination of hydrocarbon via wet deposition in city of Tehran. Polycyclic aromatic hydrocarbons, benzene, toluene, ethyl benzene and xylene, as well as fuel fingerprints containing gasoline range hydrocarbons (GRH) and diesel range hydrocarbons (DRH), are investigated.

\section{Methods and materials}

Sampling

The samples were taken in the central part of Tehran, the capital city of Iran, during the first hour of rainfall in containers with a 500-mm diameter. Collected rainwater samples were immediately sent to the laboratory for hydrocarbon analysis.

\section{Chemical and standards}

TCL polynuclear aromatic hydrocarbon mix standards were obtained from Supelco (Bellefonte, PA, USA). Gasoline range and diesel range standards were made from commercial fuels in the environmental laboratory, Faculty of Environment, University of Tehran. BTEX standards, anhydrous granular sodium sulfate, extraction solvents including hexane (Chromatographic grade), and dichloromethane (Chromatographic grade) were all purchased from Merck (Darmstadt, Germany).

Chemical analysis

One liter of each sample was extracted three times by dichloromethane using a separatory funnel following USEPA method 3510 (USEPA 1991). The extract was then cleaned up by a chromatographic column and dehydrated using $10 \mathrm{~g}$ anhydrous granulated sodium sulfate (heated for $8 \mathrm{~h}$ at $500^{\circ} \mathrm{C}$ ) and concentrated to $1 \mathrm{~mL}$ by a rotary evaporator.

A UNICAM 610 Gas Chromatograph (Unicam, Cambridge, UK) equipped with a flame ionization detector $(\mathrm{GC} /$ FID) was employed to analyze the final extract. A DB-5 column with $30 \mathrm{~m}$ length, $0.33 \mathrm{~mm} \mathrm{ID}$, and $1 \mu$ film thickness was used and the carrier gas was helium. The GC settings were as follows: injector temperature $=250^{\circ} \mathrm{C}$, detector temperature $=340^{\circ} \mathrm{C}$, oven initial temperature $=$ $45^{\circ} \mathrm{C}$, initial time $=3 \mathrm{~min}, \mathrm{ramp}=20^{\circ} \mathrm{C} / \mathrm{min}$, final temperature $=310^{\circ} \mathrm{C}$, final time $=3 \mathrm{~min}$. The injection volume was $1 \mu \mathrm{L}$ (USEPA 1991).

Quality assurance and quality control

Quality assurance and quality control (QA/QC) was detailed and comprehensive according to method $8000 \mathrm{~B}$ (USEPA 1991). Instrument blanks were performed after instrument calibration, and laboratory/extraction blanks were analyzed for each batch. No hydrocarbon residue was observed in blank samples $(n=3)$. At least four calibration standard concentrations were used for each GC run, and correlation coefficients for calibration curves was higher than 0.98 for all target compounds. Samples were analyzed in triplicate. Percent relative standard deviation (RSD) was calculated using the following equations:

$\overline{\mathrm{CF}}=\frac{\sum_{i=1}^{n} \mathrm{CF}_{i}}{n}$

$\mathrm{SD}=\sqrt{\frac{\sum_{i=1}^{n}\left(\mathrm{CF}_{i}-\overline{\mathrm{CF}}\right)^{2}}{n-1}}$

$\mathrm{RSD}=\frac{\mathrm{SD}}{\overline{\mathrm{CF}}} \times 100$

where $n$ is the number of calibration standards, SD refers to standard deviation and $\overline{\mathrm{CF}}$ is mean external standard calibration. Average RSD in this study was $4.33 \%$. Detection limit (signal/noise $=3$ ) and average percent recovery for all hydrocarbons is summarized in Table 1.

Data analysis

Statistical analysis of the results was performed using SPSS 16.0 (SPSS Inc., Chicago, IL, USA). Records were compared by ANOVA tests at the level of $p<0.05$, and the homogeneity of variance was also performed. 
Table 1 Detection limit $(\mu \mathrm{g} / \mathrm{L})$ and average recovery $(\%)$ for each hydrocarbon group

\begin{tabular}{llcc}
\hline No & Hydrocarbon & Detection limit $(\mu \mathrm{g} / \mathrm{L})$ & Average recovery $(\%)$ \\
\hline 1 & PAHs & 5 & 85.1 \\
2 & BTEX & 10 & 78.3 \\
3 & GRH & 30 & 82.1 \\
4 & DRH & 30 & 94.8 \\
\hline
\end{tabular}

\section{Results and discussion}

PAHs

The concentration of 16 polycyclic aromatic hydrocarbons, all on the USEPA priority pollutant list, was reported in Table 2.

Average $\sum$ PAHs of $452 \mu \mathrm{g} / \mathrm{L}$ show an unsafe amount. Figure 1 illustrates normal P-P Plot of expected and observed values of PAHs in Tehran rainwater; it demonstrated that expected and observed values of PAHs followed the regression line tightly and were distributed randomly and normally. In one study performed by World Meteorological Organization in 1993, the average concentrations of PAHs in the rain water (wet deposition) were reported between 0.6 and $231 \mu \mathrm{g} / \mathrm{L}$ (Esmaili-Sari 1997). The comparison of these results with the 1993 study clearly indicates that the concentration of carcinogenic PAHs doubled since 1993. Among all, Floranthene at $76 \mu \mathrm{g} / \mathrm{L}$ had the highest concentration of PAHs found. Figure 2 presents PAHs as the benzene ring numbers. Among all, three-ring PAHs (acenaphthylene, acenaphthene, fluorine, phenanthrene, anthracene) at $190 \mu \mathrm{g} / \mathrm{L}$ was the highest concentration in Tehran rainwater samples. Average fivering PAHs (benz $(a)$ anthracene, chrysene, benzo[ $b]$ fluoranthene, benzo[ $k]$ fluoranthene, benzo( $a$ )pyrene) as the most hazardous PAHs were detected at $111 \mu \mathrm{g} / \mathrm{L}$. Hollander et al. (1986) reported the concentrations of $11 \mathrm{PAH}$ in rainwater at four locations in the Netherlands in 1983. Kishida et al. (2008) determined PAHs in the air at $1.3 \mu \mathrm{g} / \mathrm{m}^{3}$ in a bus terminal in Hanoi, Vietnam. Delhomme et al. (2008) determined $\sum 16$ PAHs in France at maximum 1,596 ng/L in Strasbourg. Poster and Baker (1996) measured concentrations of PAHs in atmospheric and precipitation samples collected at a rural site adjacent to the Chesapeake Bay during late summer 1992 and determined phenanthrene at $3.6 \mathrm{ng} / \mathrm{L}$. These results demonstrate that Tehran air pollution by PAHs is of higher value than other published reports.

\section{BTEX}

Benzene, toluene, ethyl benzene, and xylene were measured for the first time in Tehran's rainwater. Among BTEX,
Table 2 Polycyclic aromatic hydrocarbons amount $(\mu \mathrm{g} / \mathrm{L})$

\begin{tabular}{rlllrr}
\hline No & Name & Abbreviation & Formula & Mean & SD \\
\hline 1 & Naphthalene & $\mathrm{NPH}$ & $\mathrm{C}_{10} \mathrm{H}_{8}$ & 27 & 5.51 \\
2 & Acenaphthylene & $\mathrm{ACY}$ & $\mathrm{C}_{12} \mathrm{H}_{8}$ & 17 & 6.08 \\
3 & Acenaphthene & $\mathrm{ACE}$ & $\mathrm{C}_{12} \mathrm{H}_{10}$ & 22 & 9.61 \\
4 & Fluorine & $\mathrm{FL}$ & $\mathrm{C}_{13} \mathrm{H}_{10}$ & 37 & 4.00 \\
5 & Phenanthrene & $\mathrm{PHE}$ & $\mathrm{C}_{14} \mathrm{H}_{10}$ & 59 & 36.86 \\
6 & Anthracene & $\mathrm{ANT}$ & $\mathrm{C}_{14} \mathrm{H}_{10}$ & 54 & 16.77 \\
7 & Fluoranthene & $\mathrm{FLT}$ & $\mathrm{C}_{16} \mathrm{H}_{10}$ & 76 & 28.54 \\
8 & Pyrene & $\mathrm{CYR}$ & $\mathrm{C}_{16} \mathrm{H}_{10}$ & 18 & 15.95 \\
9 & Benz $(a)$ anthracene & $\mathrm{C}$ & $\mathrm{C}_{18} \mathrm{H}_{12}$ & 19 & 20.66 \\
10 & Chrysene & $\mathrm{C}_{18} \mathrm{H}_{12}$ & 12 & 10.21 \\
11 & Benzo[$(b]$ fluoranthene & $\mathrm{CHR}$ & $\mathrm{C}_{20} \mathrm{H}_{12}$ & 17 & 4.04 \\
12 & Benzo $(k]$ fluoranthene & $\mathrm{BbF}$ & $\mathrm{C}_{20} \mathrm{H}_{12}$ & 15 & 4.51 \\
13 & Benzo $(a)$ pyrene & $\mathrm{BkF}$ & $\mathrm{C}_{20} \mathrm{H}_{12}$ & 49 & 15.10 \\
14 & Indeno(1,2,3-cd)pyrene & $\mathrm{IP}$ & $\mathrm{C}_{22} \mathrm{H}_{12}$ & 15 & 12.86 \\
15 & Dibenzo $(a h)$ anthracene & $\mathrm{DBA}$ & $\mathrm{C}_{22} \mathrm{H}_{14}$ & 10 & 2.02 \\
16 & Benzo $(g h i)$ perylene & $\mathrm{BghiP}$ & $\mathrm{C}_{22} \mathrm{H}_{12}$ & 16 & 5.69 \\
\hline
\end{tabular}




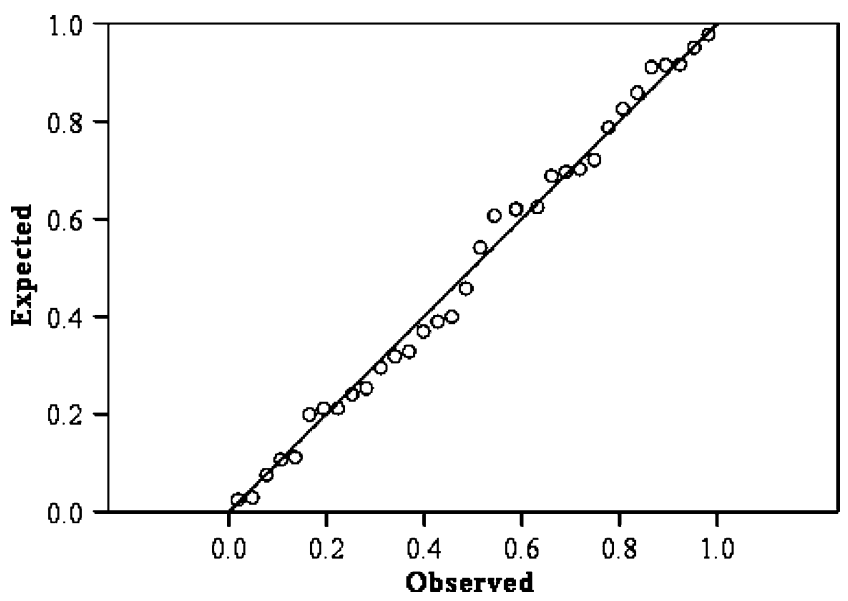

Fig. 1 Normal P-P plot of expected and observed values of PAHs in Tehran rainwater

toluene had the highest concentration of $37 \mu \mathrm{g} / \mathrm{L}$, and xylene was $21 \mu \mathrm{g} / \mathrm{L}$ which includes all three isomers ( ortho, meta, and para isomers). The concentrations of BTEX are presented in Table 3. Compared to other reports, Okochi et al. (2004) determined toluene concentration of $14.4 \mu \mathrm{g} / \mathrm{L}$ in rainwater in Yokohama, Japan. The fate of volatile organic compounds (VOCs), which are emitted into the troposphere from various anthropogenic and biogenic sources, remains to be elucidated. In general, air pollutants in the lower troposphere are dispersed by horizontal advection and upward diffusion and removed by deposition process (wet and dry deposition) and chemical transformation, depending on their physicochemical properties. Because of the toxicity of these volatile aromatic compounds (Do Rego and Pereira Netto 2007; An 2004), they should be controlled and monitored regularly in air and water environments.

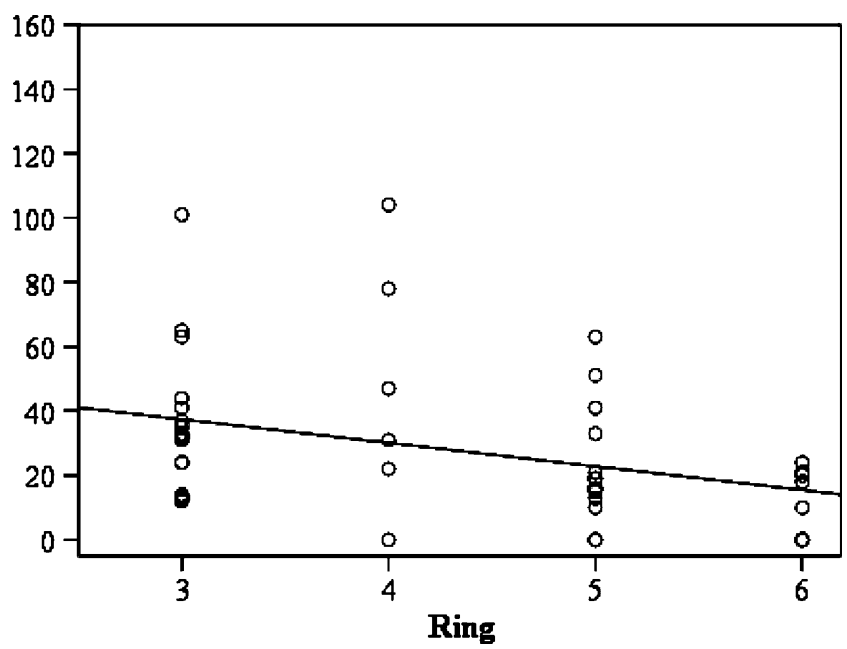

Fig. 2 Relationship between three-, four-, five- and six-ring PAHs in Tehran rainwater
Table 3 BTEX amount $(\mu \mathrm{g} / \mathrm{L})$

\begin{tabular}{lllcr}
\hline No & Name & Formula & Mean & SD \\
\hline 1 & Benzene & $\mathrm{C}_{6} \mathrm{H}_{6}$ & 25 & 8.50 \\
2 & Toluene & $\mathrm{C}_{7} \mathrm{H}_{8}$ & 37 & 12.66 \\
3 & Ethylbenzene & $\mathrm{C}_{8} \mathrm{H}_{10}$ & 16 & 14.64 \\
4 & xylene & $\mathrm{C}_{8} \mathrm{H}_{10}$ & 21 & 5.03 \\
\hline
\end{tabular}

$S D$ standard deviation

\section{GRH and DRH}

Unburned hydrocarbon emission contamination has been a serious hazard concern in the city. Employing old and low quality vehicles, substandard engines and poor gas station operation are the main cause of high amount of unburned fuels in Tehran Air. Gasoline and diesel range hydrocarbons were investigated in the Tehran rainwater samples for fuel fingerprints. GRH with the carbon range of $\mathrm{C} 5-\mathrm{C} 11$ and DRH with C12-C20 range (Verschueren 2001) were measured at $190 \pm 18$ and $950 \pm 187 \mu \mathrm{g} / \mathrm{L}$, respectively. Total fuel ( $\sum \mathrm{GRH}$ and DRH) were between 945 and $1,330 \mu \mathrm{g} / \mathrm{L}$ with an average of $1,140 \mu \mathrm{g} / \mathrm{L}$. Significant positive correlations were observed between GRH and BTEX in all samples; it highly indicated that they can be from the same sources. Nevertheless, the lack of statistically significant correlation between GRH and $\sum$ PAHs ( $p<$ 0.05 ) suggests that these hydrocarbons entered Tehran air from different sources. It is estimated that hydrocarbon fuels can enter Tehran soil ecosystems via wet and dry deposition, as well as during refueling of automobiles in the gas stations, industrial runoff, and from leakage underground fuel tanks.

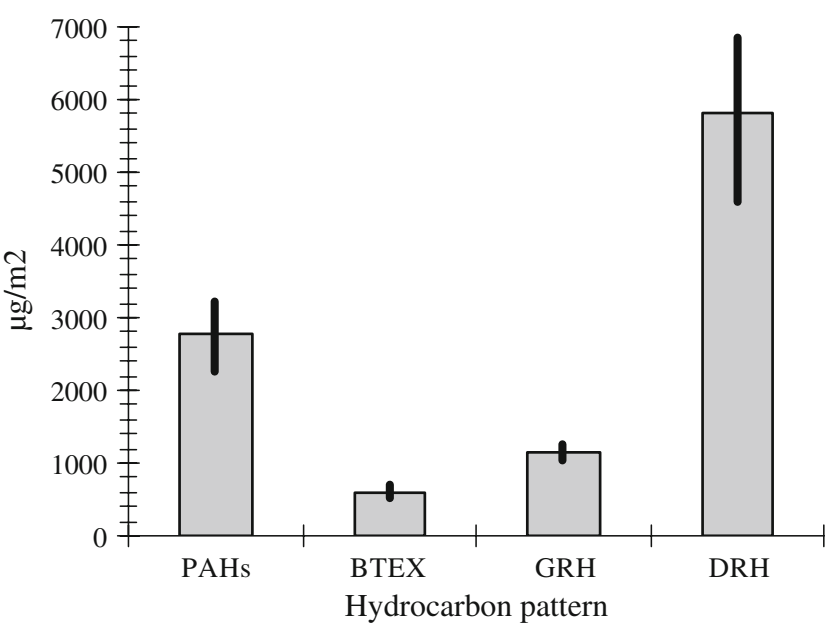

Fig. 3 Hydrocarbon transport from air to soil in city of Tehran via this wet deposition 
Pollutant transport evaluation

Pollutant transport $\left(T_{\mathrm{P}}\right)$ is a key issue in hydrocarbon monitoring in the environment. Pollutant transports $\left(\mu \mathrm{g} / \mathrm{m}^{2}\right)$ were calculated using Eq. 4:

$T_{\mathrm{P}}=\sum_{i=1}^{i=n} C_{\mathrm{p}} \times V_{\mathrm{R}}$

where $n$ is rain times, $C_{\mathrm{P}}$ is mean concentration $(\mu \mathrm{g} / \mathrm{L})$ of target pollutant, and $V_{\mathrm{R}}$ donates volume of each rainwater $\left(\mathrm{L} / \mathrm{m}^{2}\right)$. Pollution transport for each hydrocarbon group is presented in Fig. 3. Olivella (2006) reports wet deposition fluxes of the total PAHs range from 2.5 to $41 \mu \mathrm{g} / \mathrm{m}^{2} / \mathrm{month}$, in north Italy. Average $\sum$ PAHs transport in Tehran shows $2,747 \mu \mathrm{g} / \mathrm{m}^{2}$. Clearly, these are an alarming amount of hydrocarbon pollutants that eventually end up in the soil ecosystems, surface waters, and the ground waters, causing severe environmental health hazards.

\section{Conclusions}

Growing population, increased vehicular emissions, and cheap fuel prices are the major contributors to Tehran hydrocarbon air pollution. Our study demonstrated that the concentrations of hydrocarbons are extremely high in Tehran rainwater samples. Mean concentrations of $\sum 16$ PAHs was between 372 and $527 \mu \mathrm{g} / \mathrm{L}$, BTEX was between 87 and $188 \mu \mathrm{g} / \mathrm{L}$, and total fuel was between 945 and $1,330 \mu \mathrm{g} / \mathrm{L}$. Contaminated rainwater can be the major source of hydrocarbon pollution in Tehran soil and groundwater. As a conclusion, action must be taken for changing pollution status in Tehran and should focus on minimizing hydrocarbon pollution in the city.

Acknowledgements Authors would like to Acknowledge Dr. Gh. Nabi bidhendi for his support and also Dr. Shahid Kabir and Dr. Shannon Frances for their valuable comments.

Open Access This article is distributed under the terms of the Creative Commons Attribution Noncommercial License which permits any noncommercial use, distribution, and reproduction in any medium, provided the original author(s) and source are credited.

\section{References}

Achazi RK, Flenner C, Livingstone DR, Peters LD, Schaub K, Scheiwe E (1998) Cytochrome P450 and dependent activities in unexposed and PAH-exposed terrestrial annelids. Comp Biochem Physiol C Pharmacol Toxicol Endocrinol 121:339-350

An Y (2004) Toxicity of benzene, toluene, ethylbenzene, and xylene (BTEX) mixtures to sorghum bicolor and cucumis sativus. Bull Environ Contam Toxicol 72:1006-1011
Asl-Soleimani E, Farhangi S, Zabihi MS (2001) The effect of tilt angle, air pollution on performance of photovoltaic systems in Tehran. Renew Energy 24:459-468

Delhomme O, Rieb E, Millet M (2008) Polycyclic aromatic hydrocarbons analyzed in rainwater collected on two sites in east of france (strasbourg and erstein). Polycycl Aromat Compd 28:472-485

Do Rego ECP, Pereira Netto AD (2007) PAHs and BTEX in groundwater of gasoline stations from rio de janeiro city, brazil. Bull Environ Contam Toxicol 79:660-664

Esmaili-Sari A (1997) PAH's compounds in Tehran air via wet deposition. Iran J natur resour 50:23-28

Futoma DJ, Smith SR, Smith TE, Tanaka J (1981) Polycyclic aromatic hydrocarbons in water systems. CRC, Boca Raton

Halek F, Nabi Bidhendi GR, Hashtroudi M, Kavousi A (2008) Distribution of polycyclic aromatic hydrocarbons in gas phase in urban atmosphere. Int J Environ Res 2:97-102

Hollander HD, Van De Meent D, Noort PV, Wondergem E (1986) Wet deposition of polycyclic aromatic hydrocarbons in The Netherlands. Sci Total Environ 52:211-219

Hosseinpoor AR, Forouzanfar MH, Yunesian M, Asghari F, Naieni KH, Farhood D (2005) Air pollution and hospitalization due to angina pectoris in Tehran, Iran: A time-series study. Environ Res 99:126-131

IARC (2008) Air pollution, part 1, some non-heterocyclic polycyclic aromatic hydrocarbons and some related industrial exposures, international agency for research on cancer. Lyon, Paris

Jafari HR, Ebrahimi S (2007) A study on risk assessment of benzene as one of the VOCs air pollution. Int J Environ Res 1:214-217

Kakooei H, Yunesian M, Marioryad H, Azam K (2009) Assessment of airborne asbestos fiber concentrations in urban area of Tehran. Iran, Air Qualit Atmos Health 2:39-45

Kishida M, Imamura K, Takenaka N, Maeda Y, Viet PH, Bandow H (2008) Concentrations of atmospheric polycyclic aromatic hydrocarbons in particulate matter and the gaseous phase at roadside sites in hanoi, vietnam. Bull Environ Contam Toxicol 81:174-179

Maskaoui K, Hu Z (2009) Contamination and ecotoxicology risks of polycyclic aromatic hydrocarbons in shantou coastal waters, china. Bull Environ Contam Toxicol 82:172-178

Menichini E, Monfredini F, Merli F (1999) The temporal variability of the profile of carcinogenic polycyclic aromatic hydrocarbons in urban air: A study in a medium traffic area in Rome, 1993-1998. Atmos Environ 33:3739-3750

Okochi H, Sugimoto D, Igawa M (2004) The enhanced dissolution of some chlorinated hydrocarbons and monocyclic aromatic hydrocarbons in rainwater collected in yokohama, japan. Atmos Environ 38:4403-4414

Olivella MA (2006) Polycyclic aromatic hydrocarbons in rainwater and surface waters of lake maggiore, a subalpine lake in northern italy. Chemosphere 63:116-131

Pardakhti A, Esmaili Sari A, Eslami E (2004) A study on quantity of polycyclic aromatic hydrocarbons in the ambient air of the city of Tehran. J Environ Stud 30:16-20

Poster DL, Baker JE (1996) Influence of submicron particles on hydrophobic organic contaminants in precipitation. 1. concentrations and distributions of polycyclic aromatic hydrocarbons and polychlorinated biphenyls in rainwater. Environ Sci Technol 30:341-348

Roos PH, Tschirbs S, Welge P, Hack A, Theegarten D, Mogilevski G, Wilhelm M (2002) Induction of cytochrome P450 1A1 in multiple organs of minipigs after oral exposure to soils contaminated with polycyclic aromatic hydrocarbons (PAH). Arch Toxicol 76:326-334

Shirazi MA, Harding AK (2001) Ambient air quality levels in Tehran, Iran, from 1988 to 1993. Int J Environ Pollut 15:517-527

Sohrabpour M, Mirzaee H, Rostami S, Athari M (1999) Elemental concentration of the suspended particulate matter in the air of Tehran. Environ Int 25:75-81 
Sundberg K, Johansson AS, Stenberg G, Widersten M, Seidel A, Mannervik B, Jernström B (1998) Differences in the catalytic efficiencies of allelic variants of glutathione transferase $\mathrm{P} 1-1$ towards carcinogenic diol epoxides of polycyclic aromatic hydrocarbons. Carcinogenesis 19:433-436

Tsai PJ, Shihb TS, Chena HL, Leec WJ, Laid CH, Liou SH (2004) Assessing and predicting the exposures of polycyclic aromatic hydrocarbons (PAHs) and their carcinogenic potencies from vehicle engine exhausts to highway toll station workers. Atmos Environ 38:333-343

USEPA (1991) Test Method for evaluating of solid waste-SW 846. United States Environmental Protection Agency, Cincinnati

USEPA (1993) Provisional guidance for quantitative risk assessment of polycyclic aromatic hydrocarbons, EPA/600/R-93/089. US Environmental Protection Agency, Office of Research and Development, Washington, DC

Verschueren K (2001) Handbook of environmental data on organic chemicals, 4th edn. Wiley, New York
WHO (2008) Primary health care, now more than ever. World Health Organization, Geneva

Yang H, Lee S, Hsieh DPH, Chao M, Tung C (2008) PM2.5 and associated polycyclic aromatic hydrocarbon and mutagenicity emissions from motorcycles. Bull Environ Contam Toxicol $81: 412-415$

Yokoyama O, Takahashi K (2003) Planning for air pollution abatement in the greater Tehran area (GTA) in the Islamic Republic of Iran (JICA Project 1995-1997). Pure Appl Geophys 160:17-19

Zhang W, Song YF, Gong P, Sun TH, Zhou QX, Liu M (2006) Earthworm cytochrome P450 determination and application as a biomarker for diagnosing PAH exposure. J Environ Monit 8:963-967

Zrafi-Nouira I, Khedir-Ghenim Z, Zrafi F, Bahri R, Cheraeif I, Rouabhia M (2008) Hydrocarbon pollution in the sediment from the jarzouna-bizerte coastal area of tunisia (mediterranean sea). Bull Environ Contam Toxicol 80:566-572 